\title{
LEXICAL RICHNESS AND ENVIRONMENTAL LITERACY IN TEACHER TRAINING EXPLORATORY STUDY
}

\author{
RIQUEZA LÉXICA Y COMPETENCIA MEDIOAMBIENTAL EN LA \\ FORMACIÓN DEL PROFESORADO: ESTUDIO EXPLORATORIO
}

\begin{abstract}
Teaching a foreign language requires a holistic approach that involves teaching the instrumental language, its literature and its culture. Besides, it is important to highlight the role of education and values when it comes to teach English as a foreign language. During the second decade of the 21st century many natural disasters have taken place worldwide and teachers should be prepared to deal with them in the English classroom. This preparedness involves scientific knowledge together with linguistic knowledge. The main results show that the preparedness of teachers can be improved. This exploratory study has the objective to set a first approach to the preparedness of pre-service teachers to deal with the aforementioned issues through the analysis of the lexical richness of the texts they have written on environmental issues and natural disasters. The limitations of the study are bounded to the low number of samples, but it allows to explore new ways of improving language skills and environment literacy in preservice teachers which might help to provide future citizens with commitment on environmental issues. A solid scientific knowledge together with a good development of the linguistic competence are key to achieve it.
\end{abstract}

Keywords: English; Education; Environment; Lexical Richness; Writing

\section{RESUMEN}

La enseñanza de una lengua extranjera implica una aproximación holística que comprenda a la lengua, a la literatura y a la cultura. Además, es importante señalar el papel que ha de cobrar la educación en valores en lo que respecta a la enseñanza del inglés como lengua extranjera. La segunda década del siglo XXI ha estado marcada por catástrofes naturales a nivel internacional que hacen que el profesorado tenga que estar preparado para tratar estas temáticas en el aula tanto a nivel científico como a nivel lingüístico. Los principales resultados establecen que la competencia medioambiental y la competencia lingüística pueden mejorar en el profesorado en formación. Este estudio exploratorio tiene como objetivo hacer un primer acercamiento a la preparación del futuro profesorado de Educación Primaria mediante el análisis de su riqueza léxica a través de los textos que producen sobre temática medioambiental. Las limitaciones son las propias de este tipo de estudio con muestras reducidas, pero permite explorar nuevas vías para mejorar tanto la competencia lingüística como el conocimiento sobre el medioambiente para conseguir formar a una futura sociedad comprometida y sostenible. Una formación sólida a nivel lingüístico y científico pueden ser claves para conseguirlo.

Palabras clave: Inglés; Educación; Medioambiente; Riqueza léxica; Producción escrita

\footnotetext{
${ }_{1}^{1}$ Autor de correspondencia: Antonio Jesús Tinedo Rodríguez. Email: f12tiroa@uco.es
} 


\section{Introduction}

Teaching a foreign language involves a holistic action that implies teaching the language, the culture and the literature production. Besides, teaching also implies educating in values for the future citizens. People who are responsible for this action are teachers, in this case, English teachers. The question that may arise is: are teachers ready to talk about social issues by making use of the foreign language they are teaching?

The recent times have been dramatically marked by natural disasters: the high temperatures in Australia and the severe droughts have been responsible for massive bushfires in Australia meanwhile Spain suffered the effects of a deadly storm called Gloria and a few months before the Amazonia was devastated by fires. All of these natural disasters are bounded to the environment and education is supposed to play role to change the consumption habits of future generations in order to preserve the planet as we know it. Therefore, teachers should be equipped with a good environmental knowledge to create environmental awareness in the future generations. The case of English teachers is particularly peculiar due to the fact that they have an extra responsibility: teaching these values in the subject of English so that students will be able to communicate with more people to talk and to seek for solutions for that issue.

It is important to differentiate between lexical richness and lexical diversity. Lexical density can be calculated dividing the number of types into the total number of tokens (Cantos, 2013). Lexical diversity is another type of measure. According to Johansson $(2009$, p. 62) "the more varied a vocabulary a text possesses, the higher lexical diversity".

Lexical richness is bounded to lexical density, lexical variation and lexical sophistication and lexical errors in vocabulary use (Read, 2000). Ure (1971) defines lexical density as the relationship between lexical words and the total amount of words. Durán, Malvern, Richards, \& Chipere (2004) developed a more sophisticated method which perfectioned others because in their method the length of the text was not a constraint for their formula provides accurate values of lexical diversity, D, even for short texts and they took more variables into accounts; VOCD is a scale they created to measure the lexical diversity or lexical variation in a more accurate way.

There are studies on this topic like the one by Lu (2011), but the author focused on the relationship between the quality of oral narratives and lexical richness of ESL learners, in general. The innovation of this study is that it focuses on pre-service ESL teachers' lexical richness and the importance of lexical richness for environmental literacy. Nonetheless, Halliday (1985) apud Lu (2011), highlighted that spoken texts are reported to have a lower lexical density than written texts. Lu (2011) dealt with spoken texts whilst this study deals with spoken texts. Nonetheless, this is a key factor to predict the oral performance of pre-service ESL teachers which will be lower than their written performance.

Appropriate levels of lexical richness are thus crucial for teachers to teach a lesson. In this particular case, this study focuses on the environment that is why we should also take another concept into accoun, enviromental literacy:

Environmental literacy is essentially the capacity to perceive and interpret the relative health of environmental systems and take appropriate action to maintain, restore or improve the health of those systems. (Disinger \& Roth, 1992, p. 2)

A teacher thus has to be competent linguistically and scientifically. From a philological outlook we can complete this pedagogic approach by adding that a good lexical richness and an appropriate lexicon are necessary for teachers to be competent to teach environmental literacy to future generations. It means teachers should know the content and the language towards an integrated curriculum as Coyle, Holmes, \& King (2009) pointed out.

The Common European Framework of Reference for Languages establishes different levels of linguistic competence according to the Council of Europe (2001). The lexical richness of a text produced by a teacher is bounded to the different levels of the CEFRL; the higher the lexical 
richness, the higher the level of the writter. On that way, this exploratory study aims to measure the linguistic competence of pre-service teachers through their lexical richness.

The departure point is thus that in order to teach issues bounded to the environment teachers should have an adequate lexical richness that allows them to communicate in the classroom, and they should also have a good knowledge about vocabulary bounded to the environment.

\section{Objectives}

The main objectives of this study are thus knowing to which extent are teachers able to communicate ideas bounded to the environment. To do so, they have been asked to write an essay. The corpus of essays will be analysed quantitively and qualitatively to check their lexical richness and the most frequent words bounded to environmental issues that they know. Eventually, the essays will be divided into two groups: B-levels and C-levels according to the Common European Framework of Reference for Languages with the objective to decide if there are significative differences among the groups because if so, we should give a thought to increase the demands of linguistic competence of future teachers.

The initial thesis is that a high lexical richness is a crucial factor when it comes to exert a profession that requires constant communication. The main purpose of this piece of work is to study the lexical richness in EFL pre-services through the quantitative analysis of their written essays. Education involves teaching contents, but it also requires teaching values which are essential for the future citizens. Climate change and pollution are important issues and education could play a crucial role to create environmental awareness on future generation. English for Social Purposes and Cooperation is a term coined by Huertas-Abril \& Gómez-Parra (2018) which is defined as:

el proceso de enseñanza-aprendizaje del inglés como lengua extranjera en cualquier ámbito de la vida, donde además de adquirir o reforzar las competencias lingüísticas y comunicativas de la lengua, se pongan de relieve factores clave relacionados con la concienciación social, los valores cívicos y la cooperación. (p. 11)

This concept plays a key role in this study due to the fact that it implies teaching values at the same time that students are learning English. In this case we are going to focus on environmental values that is why the piece of work aims to answer the following question: Are the future teachers of English as Foreign Language linguistically and lexically ready to teach environmental values to the future generations?

\section{Methodology}

\subsection{Sample of informants and gathering instruments}

The corpus contains three texts written by pre-service teachers which are studying the Degree in Primary Education. It is important to highlight that all of them are doing a minor in English. This minor includes 24 ECTS whose contents are instrumental English, methodology and English culture. The motivation of this sample is clear because this study aims to discover if future teachers are ready to talk their future students about the environment. All of them were in their last academic course of the Primary Education degree that is why it is supposed to be an appropriate moment to carry out the text. The corpus has been analysed from a double outlook: a quantitative perspective and a qualitative perspective. Firstly, the quantitative perspective provides the reader with empirical information about the lexical richness and the lexical density of the essays of preservice teacher whilst the quantitative approach consists of an analysis of the 
content of the texts in order to create a wordlist which contains the most frequent words bounded to the environment in the essays of pre-service teachers who are also English learners.

\subsection{Procedures and data analysis}

The sample has only tree restrictions: they should be Primary teachers doing the minor in English in their last year. This sample is bounded to the objective of the study since its main goal is to know more about the lexical richness in pre-service teachers and to check their knowledge of vocabulary bounded to the environment.

Besides, they were also asked to write a text with the following conditions:

- Word limit: in order to have essays with the same amount of words. If the gathered texts have different amount of words it may affect the index of lexical richness.

- The writer cannot make use of any source of information because if s/he looks for information and words it will bias the study.

The motivation of the conditions are the following ones:

a. If pre-service teachers were not provided with an exact number of words, there is a risk of unbalanced compositions. It means, we may have got extremely longer texts and extremely short texts; it affects the representativity of the corpus because the shorter ones might be diluted into the larger ones.

b. If pre-service teachers were given the opportunity to make use of information, there would be a bias since they might look at dictionaries or translators and it directly affects the objective of the study which is measuring the lexical richness in text produced by EFL pre-service teachers in their last year.

The variables of our study are thus the following ones (see table 1):

Table 1.

Dimensions and variables

\begin{tabular}{cl}
\hline Dimension & \multicolumn{1}{c}{ Variables } \\
\hline CEFR Level & A1/A2/B1/B2/C1/C2 \\
Lexical richness & Types \\
& Token \\
& Lexical density \\
& VOCD index \\
\hline
\end{tabular}

The set of qualifications and the languages that pre-service teachers are able to speak are qualitative variables; the level of the language that they can speak is an ordinal qualitative variable because it can contain six possible answers in the CEFR (A1, A2, B1, B2, C1, C2). The field of knowledge of the qualification is also a qualitative variable and it is nominal.

The quantitative part is narrowly bounded to the third dimension: types and tokens are continuous quantitative variables. Lexical density is a variable that depends on the relationship between types and token so it is a dependent quantitative variable whose highest value can be 1 due to the fact that the calculus of lexical density consists of dividing the number of types by the number of tokens.

To analyse the data, we are going to make use of the t-student test in order to compare if there are significative differences among pre-service teachers in B levels (low and high intermediate) and pre-service teachers in $\mathrm{C}$ levels. Besides, the content analysis technique will be used to analyse the specific words bounded to the environment and the partial and total frequency of this words. On that way we would be able to check if pre-service teachers are linguistically competent to talk about the environment and if there are any differences. 
Nonetheless, the scope of this paper will only take into consideration the CEFR level, the lexical density and the VOCD index together with a content analysis due to a deeper analysis is above the scope of this piece of work.

\section{Results}

The corpus is composed by the following texts:

Table 2.

Data gathered from the texts. It includes the level of the writer and the text.

\begin{tabular}{|c|c|c|}
\hline $\begin{array}{l}\text { CFRL } \\
\text { Level }\end{array}$ & $\begin{array}{c}N . \\
\text { text }\end{array}$ & Text \\
\hline $\mathrm{C} 1$ & 1 & $\begin{array}{l}\text { It is wildly believed that nothing can be done now to rescue the environment from its current } \\
\text { situation. But is it true through? } \\
\text { In fact there are plenty of things we can do as citizens. However, bigger companies keep } \\
\text { telling us that it is our fault, but to keep buying things isn't this contradictory? } \\
\text { It is undeniable true that companies nowadays are constantly telling us to buy and to } \\
\text { consume their products, but there are also many alternatives to capitalism and pollution, so, } \\
\text { why don't we try them out? } \\
\text { Mainly because we would need to change our lifestyle and not everybody is prone to do so. A } \\
\text { change in perspective and perception is needed, but we cannot leave all the responsibility in } \\
\text { citizens. We have to blame bigger corporations too. It is vitally crucial that we stop producing, } \\
\text { not only because of the pollution generated but also because of increasing amount of rubbish }\end{array}$ \\
\hline C1 & 2 & $\begin{array}{l}\text { Seldom do we think about the environment, but it is a fact that climate change is changing our } \\
\text { habitats and ecosystems. Many different phenomena are taking place in locations which are } \\
\text { unexpected. } \\
\text { Twisters and cyclones are not usual in Spain but in the US. Nonetheless, whirlwinds have } \\
\text { been registered in the country this year. Going a step forward, hailstorms have caused a great } \\
\text { damage in the countryside and harvesters' economy is suffering a backdrop. Drought and } \\
\text { floods are dramatically being combined in sensible geographical areas and this strange } \\
\text { mixture is leading towards desertification. It is word mentioning that natural disasters such as } \\
\text { fires in rainforest are not only damaging the specific zone in which they have been produced } \\
\text { but they are also adversely affecting the whole planet due to the harm they cause to the } \\
\text { ozone layer. }\end{array}$ \\
\hline B1 & 3 & $\begin{array}{l}\text { Currently, natural catastrophes are destroying some natural areas around the planet. For } \\
\text { example, the hurricanes are appeared in some unusual zones, where some years ago it was } \\
\text { not happen, so the buildings and the cities are not built with the adequate materials to } \\
\text { avoiding several dangers. Furthermore, people do not know how to act in these situations. } \\
\text { Other natural catastrophe which is caused very important damages is the tropical raining } \\
\text { which are produced several floods around different countries. But also human beings are } \\
\text { killing the planet too, for instance, when someone provoke a forest fire, it does not matter the } \\
\text { reason why this individual does it. He or she is putting all the natural environment and also the } \\
\text { society in danger. These problems are affected in a bad way to the planet due to the fact that } \\
\text { some species could be extinguished, owing to these factors. }\end{array}$ \\
\hline B1 & 4 & $\begin{array}{l}\text { There are a lot of natural disasters in our planet and nowadays there are increasing because } \\
\text { of the humans. The disaster could be about water, wind, illnesses, fire on earth. Humans are } \\
\text { changing the climate using our pollution and it produces that the disaster be more } \\
\text { catastrophe. For example, it is natural at this day to have floods because of intense rain and, } \\
\text { of course, there are more fires produced by the humans. We are destroying the world and the } \\
\text { worst is that the problems of the natural disasters are being suffered by the poor people. I } \\
\text { mean, when there is a hurricane or a flood, poor people have worse houses and less } \\
\text { resources and the lose all with this natural disaster, meanwhile rich people live in places } \\
\text { where there are not to much disasters and they have better conditions to battle them. }\end{array}$ \\
\hline
\end{tabular}

Through a statistical analysis we obtain the following data: 
Table 3.

Statistical analysis of the LD-index and the VOCD-index of each text

\begin{tabular}{cccc}
\hline Text & CEFRL level & LD & VOCD \\
\hline 1 & C1 & 0.59 & 82.19 \\
2 & C1 & 0.69 & 83.82 \\
3 & B1 & 0.67 & 84.88 \\
4 & B1 & 0.59 & 60.80 \\
\hline
\end{tabular}

Regarding LD, an applying the t-test to check if there is any significative difference, we can conclude that the two-tailed $P$ value equals 0.8902 ; it means that difference is not statistically significant:

Table 4.

Statistical analysis of the LD-index by levels of competence of the CEFR

\begin{tabular}{ccc}
\hline Group & C1 & B1 \\
\hline Mean & 0.6400 & 0.6300 \\
SD & 0.0707 & 0.0566 \\
SEM & 0.0500 & 0.0400 \\
N & 2 & 2 \\
\hline
\end{tabular}

Regarding the VOCD index, an applying the t-test to check if there is any significative difference, we can conclude that that the two-tailed $P$ value equals 0.4883 ; it means that difference is not statistically significant.

Table 5.

Statistical analysis of the VOCD-index by levels of competence of the CEFR

\begin{tabular}{ccc}
\hline Group & C1 & B1 \\
\hline Mean & 83.0050 & 72.8400 \\
SD & 1.1526 & 17.0271 \\
SEM & 0.8150 & 12.0400 \\
N & 2 & 2 \\
\hline
\end{tabular}

Nonetheless, from a qualitative outlook there are differences between the groups; one of these factors, as stated in the theorical framework, was the amount lexical errors in vocabulary. It also affects the lexical richness. The B1 learners have had this sort of errors by using expression such as "torrential raining" or by saying that "hurricanes are appeared" or "tropical raining".

To analyse the exact terms which are bounded to the environment a chart and a table with the frequency of those terms have been designed: 
Table 6.

Table of frequency of appearance of terms bounded to the environment

\begin{tabular}{cc}
\hline Term & Frequency \\
\hline Environment & 3 \\
Pollution & 2 \\
Rubbish & 1 \\
Climate change & 1 \\
Habitats & 1 \\
Ecosystems & 1 \\
Phenomena & 1 \\
Twisters & 1 \\
Cyclones & 1 \\
Whirlwinds & 1 \\
Hailstorms & 1 \\
Countryside & 1 \\
Harvesters & 1 \\
Droughts & 1 \\
Floods & 3 \\
Desertification & 1 \\
Fires & 3 \\
Rainforest & 1 \\
Planet & 2 \\
Ozone layer & 1 \\
Natural disasters & 5 \\
Hurricanes & 2 \\
Catastrophe & 2 \\
Extinguished & 1 \\
Water & 1 \\
Wind & 1 \\
Ilnesses & Rain \\
World & 1 \\
\hline & \\
\hline
\end{tabular}

This final analysis shows that there are terms and collocations such as "natural disasters" which are too general and have been used with a high frequency whilst there are others such as ecosystems, synonyms for wind phenomena (whirlwinds, cyclones, etc.) which only have been used once in the whole corpus.

\section{Discussion and conclusion}

From the data in the former section we can conclude that there are no significant variations between pre-service EFL teachers with B or $C$ levels when it comes to lexical density or VOCD index. Nonetheless, it is worth mentioning that the sample is really small and thus, not representative. An observation is that the author of text number 3 might have a higher level due to the fact that the survey explicitly asked for accreditations but this pre-service teacher could be about doing the B2 exam and that is why there is such a big difference between text 3 and 4 and 
it could also be the reason why there is not statistical support to differentiate between $B$ and $C$ levels.

Another worth mentioning aspect is that the text number 2 contains most of the words related to the environment its author uses them properly whilst the authors of text 3 and text 4 commit important errors bounded to collocations or uses of the vocabulary. Qualitatively, we find a difference among levels.

Nonetheless, the conclusion is that a total amount of 29 terms bounded to environment in four texts which explicitly asked student for writing an essay on environment is not enough. The conclusion is that they need specific training on environment literacy because if we pay attention to the definition of environmental literacy by Disinger \& Roth (1992) we reach the conclusion that the texts do not show a deep understanding of environmental issues. Besides if we look for an integrated curriculum as Coyle, Holmes, \& King (2009) pointed out teachers should be linguistically equipped for their future lessons. We should not forget that our measures have been applied to written texts and lessons are mainly based on spoken language, so all of the indexes are supposed to be lower as Lu (2011) pointed out in his study.

Therefore, future lines of research could be about developing study plans for pre-service teachers in order to increase both their environmental literacy and their lexical richness. These plans could be part of life-long learning programmes which might serve for both pre-service teachers and teachers who need it.

Finally, it is important to highlight that the sample was really small and therefore, the results are not reliable. Future research could include a bigger sample and an improvement of the survey by separating items. Besides, it could be interesting to analyse other variables such as gender, ways of studying vocabulary, etc., which have not been analysed in this paper.

\section{References}

Cantos, P. (2013). Statistical Methods in Language and Linguistic Research. Milton Keynes: Equinox.

Council of Europe. Council for Cultural Co-operation. Education Committee. Modern Languages Division. (2001). Common European Framework of Reference for Languages: learning, teaching, assessment. Europe: Cambridge University Press.

Coyle, D., Holmes, B., \& King, L. (2009). Towards an integrated curriculum-CLIL National Statement and Guidelines. London: The Languages Company.

Disinger, J. F., \& Roth, C. E. (1992). Environmental Literacy. ERIC/CMEE Digest.

Durán, P., Malvern, D., Richards, B., \& Chipere, N. (2004). Developmental Trends in Lexical Diversity. Applied Linguistics, 25(2), 220-242. https://doi.org/10.1093/applin/25.2.220

Halliday, M. (1985). Spoken and written language. Melborne, Australia: Deakin University Press.

Huertas-Abril, C. A., \& Gómez-Parra, M. E. (2018). Inglés para fines sociales y de cooperación: Guía para la elaboración. Barcelona: Graó.

Johansson, V. (2009). Lexical diversity and lexical density in speech and writing: A developmental perspective. Lund Working Papers in Linguistics, 53, 61-79.

Lu, X. (2011). The Relationship of Lexical Richness to the Quality of ESL Learners' Oral Narratives. The Modern Language Journal, 190-208.

Read, J. (2000). Assessing vocabulary. Oxford: Oxford University Press.

Text Inspector. (2020). Text Inspector. Retrieved from WebLingua: https://textinspector.com/ 
Ure, J. (1971). Lexical density and register differentiation. In G. E. Perren \& J. L. M. Trim (Eds.), Applications of linguistics: Selected papers of the Second International Congress of Applied Linguistics, Cambridge 1969 (pp. 443-452). Cambridge: Cambridge University Press. 